\title{
New Insights in Physical Therapy and Rehabilitation in Axial Spondyloarthritis: A Review
}

\author{
Fabio Massimo Perrotta (D) - Antonio Musto $\cdot$ Ennio Lubrano
}

Received: July 11, 2019 / Published online: August 13, 2019

(C) The Author(s) 2019
Enhanced Digital Features To view enhanced digital features for this article go to: https://doi.org/10.6084/ m9.figshare.9225272.

F. M. Perrotta $(\bowtie) \cdot$ E. Lubrano

Academic Rheumatology Unit, Dipartimento di Medicina e Scienze della Salute "Vincenzo Tiberio", Università Degli Studi del Molise, Campobasso, Italy e-mail: f.perrotta85@gmail.com

A. Musto

U.O.S. di Riabilitazione e Prevenzione Cardiologica, Ospedale "Antonio Cardarelli", Campobasso, Italy
Keywords: Ankylosing spondylitis; Nonradiographic axial spondyloarthritis; Physiotherapy; Rehabilitation; Treatment

\section{INTRODUCTION}

Axial spondyloarthritis (axSpA) is a group of chronic inflammatory diseases that affect mainly the axial skeleton, with a possible association with other articular and extra-articular manifestations. A hallmark of these conditions is the presence of inflammatory back pain due to the development of enthesitis, especially at the level of the sacro-iliac joints and spine, with the possible involvement of peripheral entheseal structures such as Achille's tendon insertion $[1,2]$. A few years ago, the Assessment of SpondyloArthritis International Society (ASAS) proposed and validated classification criteria for axSpA [2], which included both non-radiographic axSpA (nr-axSpA) and radiographic axSpA or ankylosing spondylitis (AS). This latter entity is characterized by new bone formation and ankylosis in sacro-iliac joints and spine, leading to functional impairment, postural alterations, deformity, and disability, with a significant reduction of quality of life, especially for patients with long-standing disease [2]. In the last 15 years, treatment of axSpA has been revolutionized since the introduction of biologic drugs. Anti-tumor necrosis factor (TNF) and anti-interleukin (IL) 17 proved efficacy and 
effectiveness in randomized clinical trials (RCTs) and in real-life settings in the reduction of pain, spinal inflammation, and in the induction of a status of low disease activity and remission. These drugs also demonstrated efficacy in the improvement of articular function and quality of life. Furthermore, recent data seem to suggest a reduction in the progression of spinal damage [3-7]. However, unmet needs still remain for patients being intolerant or nonresponders to biologic drugs and despite the development of new treatments, physical therapy and rehabilitation are of crucial importance in the management of axSpA patients [7].

The aim of this paper is to review the most updated evidence on the role of physical therapy and rehabilitation in both AS and nr-axSpA, with a focus on the assessment of patients and on the new instruments and approaches. A search on PubMed using the terms "assessment", "physical therapy", "rehabilitation", "exercise", "axial spondyloarthritis", and "ankylosing spondylitis" was performed. This article is based on previously conducted studies and does not contain any studies with human participants or animals performed by any of the authors.

\section{ASSESSMENT}

The assessment of axSpA patients can be a complex process and has to take into account several factors comprising, but not limited to, disease activity, pain, articular function, quality of life, workability, and psychological factors. Recommendations for outcome assessment of AS were proposed by the ASAS/Outcome Measures in Rheumatology (OMERACT) group about 20 years ago [8].

The nine previously selected domains comprised pain, stiffness, physical function, fatigue, spinal mobility, peripheral joints, enthesis, $\mathrm{X}$-rays of the spine, and laboratory assessment of inflammation. The ASAS/OMERACT Core Set was not primarily developed to assess the impact of the disease on functioning but to measure all aspects of outcome. Moreover, the ASAS/OMERACT Core Set recommendations proposed the minimal domains to be measured in trials or for clinical record. In 2010, an International Classification of Functioning, Disability and Health (ICF) core set was developed and included in the Brief ICF Core Set for AS, with the aim to represent the new reference to define functioning in AS and facilitate clinicians' and researchers' efforts to incorporate a patient-oriented, multilevel, and comprehensive view on functioning in axSpA [9]. More recently, the ASAS/OMERACT groups developed a new core set of domains, representing the minimum of variables that should be collected for both AS and nr-axSpA. Specific instruments for the assessment of function, pain, fatigue, and quality of life were developed and proposed. The Bath Ankylosing Spondylitis Disease Activity Index (BASDAI) that encompasses six items, and the new index Ankylosing Spondylitis Disease Activity Score (ASDAS) that comprises the evaluation of $C$ reactive protein (CRP), should be used to assess disease activity. Two indices should be used to measure function in axSpA: the Bath Ankylosis Spondylitis Functional Index (BASFI) and the Dougados Functional Index (DFI), while, to assess spinal stiffness and pain, the visual analogue scale is used. The assessment of spinal mobility should be performed using the Bath Ankylosing Spondylitis Metrology Index (BASMI) that measures the mobility of the spine. To evaluate quality of life, composite outcome measure should be used, such as the ASAS Health Index and the AS quality of life (ASQOL) questionnaire [10]. ASAS has brought parsimony in this multitude of outcome measures by prioritizing aspects of validity and feasibility. These indices will help to create a better understanding of all aspects of axSpA, and are widely used to evaluate the efficacy and effectiveness of physical therapy intervention in most of the studies and in clinical practice.

\section{PHYSIOTHERAPY AND EXERCISE IN AXSPA}

Physiotherapy interventions for axSpA have shown to be an important part of the management of the disease, with a tendency to be more effective when done as a supervised outpatient 
group [11]. The cornerstone of physical therapy in axSpA is exercise, which is performed with the aim of reducing important components of the burden of axSpA such as pain, stiffness, and to improve function.

Studies on the biopsychosocial approach have shown the relationship between disability and chronic pain. Pain and pain-related disability will affect individuals biologically, psychologically, and socially. Some studies have shown that pain-related behavior causes learning of avoidance. Individuals are not able to sustain the activities that they believe will increase their pain for a long time. Avoidance of long-duration movements leads to a reduction in motor activities due to physical (incapacity syndrome as a result of loss of mobility and muscle strength) and psychological (depression and loss of self-esteem) factors [12, 13]. Together with anatomical changes due to new bone formation, pain-related behavior represents an important aspect that should be taken into account in patients with axSpA starting physical therapy.

Regular exercise is considered to be a key component in the management of axSpA [7] and has shown to reduce disease activity, pain, and stiffness and improve physical functioning, chest expansion, spinal mobility, and cardiorespiratory function in $\mathrm{axSpA}$ patients. It also has the potential to reduce depressive symptoms [14-16]. Supervised group exercise showed a greater improvement in quality of life, spinal mobility, and patient global assessment than unsupervised, individual exercise programs [17].

\section{NON-RADIOGRAPHIC AXIAL SPONDYLOARTHRITIS}

Evidence of the effectiveness of physiotherapy on the "early" stage of AS and in nr-axSpA are recent, since the introduction of ASAS criteria in 2006. Interestingly, Levitova et al. recently showed that exercise therapy is beneficial for both radiographic and non-radiographic subgroups of axSpA, using a combination of different methods (strengthening and spinal traction, spinal exercises, posture correction, elements derived from Pilates, muscle stretching, and home-made based exercise). In addition to a better mobility, disease activity assessed with ASDAS improved after an intensive exercise program. Furthermore, a decrease in serum calprotectin levels in both axSpA subgroups was found, suggesting improvement even in the objective inflammatory markers [18].

Recently, benefits of exercise in axSpA on both clinical and laboratory parameters of bone turnover was studied: in a study aimed to investigate the patient-reported outcomes and extracellular matrix-derived biomarkers in both AS and nr-axSpA after exercise intervention, global disease activity improved significantly, and the change in disease activity was almost identical for nr-axSpA and AS. However, the quality of life was not changed and biomarkers were not influenced by exercise therapy. This indicates that exercise therapy is important for patients' health but it seems to not affect extracellular matrix turnover [19].

However, the evidence of effectiveness of rehabilitation programs and physiotherapy in the early stages of axSpA is still lacking because of the limited number of studies performed on this subset and the different approach used for physical therapy. Furthermore, studies on this aspect showed controversial results. In a recent study involving the DESIR cohort, no functional improvement in patients with early axSpA treated with early physical therapy (at least eight supervised sessions of physical therapy during the first 6 months) was found, and the authors concluded that it seems to be no functional benefit for patients with early SpA treated early by physiotherapy in daily clinical practice [20]. On the other hand, recent work revealed a beneficial effect of McKenzie training in patients with early SpA: after 12 and 24 weeks of exercises, Rosu et al. reported significant improvement in pain, metrology, disease activity, and function in the McKenzie group in respect to patients treated with classic kinetic exercises and concluded that specific McKenzie training should be included in the standard care, especially in early axial disease patients [21]. 


\section{ANKYLOSING SPONDYLITIS}

The most important advances in the field of physical therapy in AS are summarized in two recent publications [22, 23]. Zäo and Cantista conducted a systematic review of 35 clinical trials, the majority of which showed positive effects of physical exercise in the control of disease activity, pain, mobility, function, and quality of life. Pécourneau et al. [22, 23] performed a meta-analysis that combined data from eight RCTs comparing exercises versus a control group and showed a significant improvement in disease activity (measured with the BASDAI) and physical function (measured with the BASFI). The magnitude of the effect is largest in the RCTs in which aerobic and strengthening programs predominate over the classic stretching and breathing programs $[24,25]$. Recently, the added value of hydrotherapy and education within the standard group exercise was demonstrated [22].

However, although exercise programs showed efficacy in AS, the fear that physical activity may cause pain as a result of kinesiophobia in individuals will cause a decrease in muscular strength and functional activities and in the ability to move in the long term [12]. This aspect should be carefully evaluated in the management of patients.

Most studies showed a statistically significant improvement with exercise programs in several outcomes: pain, disease activity, mobility, function, cardiorespiratory function, depression, and quality of life. The improvement was not statistically significant in all outcomes measured only in three studies, namely in the study conducted by Altan et al., which intervention was based on Pilates [26] and in two other studies concerning home exercise, in which there were statistically significant improvements regarding mobility but not in disease activity and functionality $[27,28]$. Home exercise has proven to be beneficial when performed five times per day, at least for $30 \mathrm{~min}$. Its effect may be limited by poor compliance or incorrect understanding on how to perform the exercises. Thus, it is essential to invest in teaching exercise performance correctly.

A combined exercise program (range of motion, strengthening, and aerobic exercises) seems to be more beneficial than range of motion exercises alone [22].

\section{COMBINED PHARMACOLOGICAL AND REHABILITATION PROGRAMS}

With the development of biologic drugs, the possibility to combine effective pharmacological treatment strategies with rehabilitation programs was explored [29].

Different studies showed that the combination therapy of anti-TNF treatment plus rehabilitation was more effective in terms of symptom severity, functional and quality of life indices, activities of daily living, exercise parameters, and anthropometric measurements, compared with biologic alone. In most of the studies involving TNF inhibitor therapy, the patients were stabilized on their TNF inhibitor before the start of the rehabilitation program.

In two studies, in which patients with AS were initiated to etanercept after they had undergone intensive rehabilitation or at the same time as starting exercise therapy, the combination improved function, disability, and quality of life compared to either rehabilitation without etanercept or with etanercept alone [29].

A cross-sectional survey of 32 AS patients showed that levels of home-based patient exercise (walking and swimming) increased with anti-TNF compared with prior to anti-TNF treatment [30]. In addition, patients perceived mild to moderate benefits in stiffness, function, fitness, and overall outcome from physical therapy and anti-TNF, and motivation levels for exercise improved significantly with anti-TNF treatment. A second study in which patients started a rehabilitation program before anti-TNF therapy showed that although patients achieved improved metrology (spine mobility/ stiffness), pain and disease activity on rehabilitation alone, further significant improvements in mobility, pain, and disease activity were seen 
when patients started anti-TNF therapy together with improvements in function and fitness. Data from these reports suggest that combined anti-TNF therapy plus physiotherapy is more effective in terms of symptom severity, disease activity, disability, and quality-of-life indices versus biologic alone or rehabilitation with standard medical therapy, or, in non-comparative studies, compared with baseline. The most effective rehabilitation appears to be supervised or performed with in-patient programs with an educational component. Available data do not provide guidance on most appropriate endpoints or identify patients most likely to benefit from combination therapy. Combined, TNF inhibitor and rehabilitation therapy appear to have a synergistic effect, possibly due to increased adherence to exercise [29-32].

\section{CARDIORESPIRATORY EXERCISE}

In the general population, it is well known that cardiorespiratory exercise has beneficial effects on general health, emotional distress, fatigue, and mood [33]. This aspect was investigated in patients with axSpA: in a recent study, axSpA patients fulfilling the ASAS criteria were enrolled to perform high-intensity interval exercise on a treadmill (4 min of walking/running at $90-95 \%$ of maximal heart rate followed by 3 min of active resting at $70 \%$ of maximal heart rate), repeated four times 2 days a week. Authors reported a significant beneficial effect of the intervention on fatigue, emotional distress, and ability to do the day's activity [34].

Karapolat et al. investigated the effects of adding aerobic exercise to a stretching and mobility exercise program. The addition of swimming significantly increased walking distance on 6-min walk test compared to exercise alone, but no significant between-group differences were observed in cardiorespiratory variables [35]. Niedermann et al. found that the addition of aerobic training to a flexibility program increased cardiorespiratory fitness measured with a submaximal bicycle test, but did not result in a significant difference in cardiovascular risk factors (cholesterol and triglycerides) [36]. There were no significant between- group differences in disease activity, quality of life or spinal mobility. Following a 3-month multimodal group exercise intervention, a significant improvement was observed in physical work capacity on a bicycle ergometer and predicted vital capacity [37]. Durmus et al. [38] reported a significant increase in distance walked in a 6-min walk test following exercise compared to controls; no significant betweengroup differences were observed in pulmonary function tests $[15,38]$.

\section{EDUCATION}

Education is an important part of the management of axSpA. A discussion on the definition and symptoms of the disease, findings, impacts on internal organs, pharmacological treatments, benefits of surgical procedures, dieting and weight control, together with providing general principle of anatomy and physiology of the spine, is of crucial importance in maintaining compliance and benefits of rehabilitative programs.

Patients with AS showed a high level of knowledge of their disease, although some wrong beliefs about the role of blood tests, the HLA-B27 antigen, and inheritance was observed [39]. However, poor information is available on their knowledge about exercise programs. A recent study showed a significant improvement in disease activity, quality of life, and spinal mobility at the end of the 3-month period in AS patients receiving educational programs in respect to the control group. This finding suggests that educational programs and group exercise sessions held in controlled hospital setting promote better improvement [40]. More recently, with the widespread access to web applications, physician have the possibility of prescribing exercises in patients with axSpA combined with a specific training program following a web application based on multimedia animations and, potentially, increase a patient's compliance and satisfaction [41].

Furthermore, helping rheumatologists and other physicians who treat patients with axSpA to know the benefits and limitations of exercise 
and to prescribe it, with educational sessions, could be useful to better manage patients.

\section{CONCLUSIONS}

Current evidence has demonstrated the beneficial effects of physiotherapy in patients with AS. However, the effects on nr-axSpA are still debated and further evidence is needed to support this approach. Expanding traditional programs of exercises to include aerobic components, cardiorespiratory exercises, and educational programs may improve clinical outcomes, although the most effective exercise protocol still remains unclear.

\section{ACKNOWLEDGEMENTS}

Funding. No funding or sponsorship was received for this study or for the publication of this article.

Authorship. All named authors meet the International Committee of Medical Journal Editors (ICMJE) criteria for authorship for this article, take responsibility for the integrity of the work as a whole, and have given their approval for this version to be published.

Disclosures. Ennio Lubrano is a member of the journal's Editorial Board. Fabio Massimo Perrotta and Antonio Musto have nothing to disclose.

Compliance with Ethics Guidelines. This article is based on previously conducted studies and does not contain any studies with human participants or animals performed by any of the authors.

Open Access. This article is distributed under the terms of the Creative Commons Attribution-NonCommercial 4.0 International License (http://creativecommons.org/licenses/ by-nc/4.0/), which permits any noncommercial use, distribution, and reproduction in any medium, provided you give appropriate credit to the original author(s) and the source, provide a link to the Creative Commons license, and indicate if changes were made.

\section{REFERENCES}

1. Sieper J, Poddubnyy D. Axial spondyloarthritis. Lancet. 2017;390(10089):73-84.

2. Rudwaleit M, van der Heijde D, Landewé R, Listing J, Akkoc N, Brandt J, et al. The development of Assessment of SpondyloArthritis international Society classification criteria for axial spondyloarthritis (part II): validation and final selection. Ann Rheum Dis. 2009;68:777-83.

3. Callhoff J, Sieper J, Weiß A, Zink A, Listing J. Efficacy of TNF $\alpha$ blockers in patients with ankylosing spondylitis and non-radiographic axial spondyloarthritis: a meta-analysis. Ann Rheum Dis. 2015;74(6):1241-8.

4. Lubrano E, Perrotta FM, Marchesoni A, D'Angelo S, Ramonda R, Addimanda $\mathrm{O}$, et al. Remission in nonradiographic axial spondyloarthritis treated with anti-tumor necrosis factor- $\mathrm{E} \pm$ drugs: an Italian multicenter study. J Rheumatol. 2015;42:258-63.

5. Lubrano E, De Socio A, Perrotta FM. Unmet needs in axial spondyloarthritis. Clin Rev Allergy Immunol. 2018;55(3):332-9.

6. Braun J, Haibel H, de Hooge M, Landewé R, Rudwaleit M, Fox T, et al. Spinal radiographic progression over 2 years in ankylosing spondylitis patients treated with secukinumab: a historical cohort comparison. Arthritis Res Ther. 2019;21(1):142. https://doi.org/10.1186/s13075-019-1911-1.

7. van der Heijde D, Ramiro S, Landewé R, Baraliakos X, Van den Bosch F, Sepriano A, et al. 2016 update of the ASAS-EULAR management recommendations for axial spondyloarthritis. Ann Rheum Dis. 2017;76(6):978-91.

8. van der Heijde D, Calin A, Dougados $\mathrm{M}$, et al. Selection of instruments in the core set for DC-ART, SMARD, physical therapy, and clinical record keeping in ankylosing spondylitis. Progress report of the ASAS Working Group. Assessments in Ankylosing Spondylitis. J Rheumatol. 1999;26:951-4.

9. Boonen A, Braun J, van der Horst Bruinsma IE, Huang F, Maksymowych W, Kostanjsek N, et al. ASAS/WHO ICF core sets for ankylosing spondylitis (AS): how to classify the impact of AS on 
functioning and health. Ann Rheum Dis. 2010;69(1):102-7.

10. Landewé R, van Tubergen A. Clinical tools to assess and monitor spondyloarthritis. Curr Rheumatol Rep. 2015;17(7):47. https://doi.org/10.1007/ s11926-015-0522-3.

11. Lubrano E, D'Angelo S, Spadaro A, Palazzi C, Olivieri I. Rehabilitation for ankylosing spondylitis in the era of biologics: any room left for this treatment? J Rheumatol. 2011;38(7):1228-30.

12. Er G, AngIn E. Determining the relationship of kinesiophobia with respiratory functions and functional capacity in ankylosing spondylitis. Med (Baltim). 2017;96(29):e7486.

13. Vlaeyen JW, Kole-Snijders AM, Boeren RG, et al. Fear of movement/(re)injury in chronic low back pain and its relation to behavioral performance. Pain. 1995;62:363-72.

14. Regel A, Sepriano A, Baraliakos X, van der Heijde D, Braun J, Landewe R, et al. Efficacy and safety of non-pharmacological and non-biological pharmacological treatment: a systematic literature review informing the 2016 update of the ASAS/EULAR recommendations for the management of axial spondyloarthritis. RMD Open. 2017;3(1):e000397.

15. O'Dwyer T, O'Shea F, Wilson F. Exercise therapy for spondyloarthritis: a systematic review. Rheumatol Int. 2014;34(7):887-902.

16. Redeker I, Hoffmann F, Callhoff J, Haibel H, Sieper J, Zink A, et al. Determinants of psychological wellbeing in axial spondyloarthritis: an analysis based on linked claims and patient-reported survey data. Ann Rheum Dis. 2018;77:1017-24.

17. Hilberdink B, van der Giesen F, Vliet Vlieland T, van Gaalen F, van Weely S. Supervised group exercise in axial spondyloarthritis: patients' satisfaction and perspective on evidence-based enhancements. Arthritis Care Res (Hoboken). 2019;1:1. https://doi. org/10.1002/acr.23892.

18. Levitova A, Hulejova $H$, Spiritovic M, Pavelka K, Senolt L, Husakova M. Clinical improvement and reduction in serum calprotectin levels after an intensive exercise programme for patients with ankylosing spondylitis and non-radiographic axial spondyloarthritis. Arthritis Res Ther. 2016;18(1):275.

19. Husakova M, Siebuhr AS, Pavelka K, Spiritovic M, Bay-Jensen AC, Levitova A. Changes of patient-reported outcomes and protein fingerprint biomarkers after exercise therapy for axial spondyloarthritis. Clin Rheumatol. 2019;38(1):173-9.
20. Escalas C, Dalichampt M, Dougados M, Poiraudeau S. Evaluation of physiotherapy in a prospective cohort of early axial spondyloarthritis. Data from the DESIR cohort. Joint Bone Spine. 2016;83(2):185-90.

21. Rosu OM, Ancuta C. McKenzie training in patients with early stages of ankylosing spondylitis: results of a 24-week controlled study. Eur J Phys Rehabil Med. 2015;51(3):261-8.

22. Zao A, Cantista P. The role of land and aquatic exercise in ankylosing spondylitis: a systematic review. Rheumatol Int. 2017. https://doi.org/10. 1007/s00296-017-3829-8.

23. Pecourneau V, Degboe Y, Barnetche T, Cantagrel A, et al. Effectiveness of exercise programs in ankylosing spondylitis: a meta-analysis of randomized controlled trials. Arch Phys Med Rehabil. 2018;99(2):383-9.

24. Kjeken I, Bo I, Ronningen A, Spada C, et al. A 3-week multidisciplinary in-patient rehabilitation programme had positive long-term effects in patients with ankylosing spondylitis: randomized controlled trial. J Rehabil Med. 2013;45(3):260-7.

25. Sveaas SH, Berg IJ, Provan SA, Semb AG, et al. Efficacy of high intensity exercise on disease activity and cardiovascular risk in active axial spondyloarthritis: a randomized controlled pilot study. PLoS ONE. 2014;9(9):e108688.

26. Altan L, Korkmaz N, Dizdar M, Yurtkuran M. Effect of Pilates training on people with ankylosing spondylitis. Rheumatol Int. 2012;32(7):2093-9.

27. Widberg K, Karimi H, Hafström I. Self- and manual mobilization improves spine mobility in men with ankylosing spondylitis-a randomized study. Clin Rehabil. 2009;23(7):599-608.

28. Sweeney S, Taylor G, Calin A. The effect of a home based exercise intervention package on outcome in ankylosing spondylitis: a randomized controlled trial. J Rheumatol. 2002;29(4):763-6 [Internet].

29. Lubrano E, Spadaro A, Amato G, Benucci M, Cavazzana I, Chimenti MS, et al. Tumour necrosis factor alpha inhibitor therapy and rehabilitation for the treatment of ankylosing spondylitis: a systematic review. Semin Arthritis Rheum. 2015;44(5):542-50.

30. Dubey SG, Leeder J, Gaffney K. Physical therapy in anti-TNF treated patients with ankylosing spondylitis. Rheumatol (Oxf). 2008;47:1100-1.

31. Giannotti E, Trainito S, Arioli G, Rucco V, Masiero $S$. Effects of physical therapy for the management of 
patients with ankylosing spondylitis in the biological era. Clin Rheumatol. 2014;33(9):1217-30.

32. Lubrano E, D'Angelo S, Parsons WJ, Serino F, Tanzillo AT, Olivieri I, et al. Effects of a combination treatment of an intensive rehabilitation program and etanercept in patients with ankylosing spondylitis: a pilot study. J Rheumatol. 2006;33:2029-34.

33. Peluso MA, Guerra de Andrade LH. Physical activity and mental health: the association between exercise and mood. Clin (Sao Paulo). 2005;60:61-70.

34. Sveaas SH, Berg IJ, Fongen C, Provan SA, Dagfinrud H. High-intensity cardiorespiratory and strength exercises reduced emotional distress and fatigue in patients with axial spondyloarthritis: a randomized controlled pilot study. Scand J Rheumatol. 2018;47(2):117-21.

35. Karapolat H, Eyigor S, Zoghi M, Akkoc Y, Kirazli Y, Keser G. Are swimming or aerobic exercise better than conventional exercise in ankylosing spondylitis patients? A randomized controlled study. Eur J Phys Rehabil Med. 2009;45(4):449-57.

36. Niedermann K, Sidelnikov E, Muggli C, Dagfinrud H, Hermann M, Tamborrini G, et al. Cardiovascular training improves fitness in patients with ankylosing spondylitis. Arthritis Care Res (Hoboken). 2013. https://doi.org/10.1002/acr.22062.

37. Ince G, Sarpel T, Durgun B, Erdogan S. Effects of a multimodal exercise program for people with ankylosing spondylitis. Phys Ther. 2006;86(7):924-35.

38. Durmus D, Alayli G, Uzun O, Tander B, Canturk F, Bek Y, et al. Effects of two exercise interventions on pulmonary functions in the patients with ankylosing spondylitis. Joint Bone Spine. 2009;76(2):150-5.

39. Lubrano E, Helliwell P, Moreno P, Griffiths B, Emery $P$, Veale D. The assessment of knowledge in ankylosing spondylitis patients by a self-administered questionnaire. Br J Rheumatol. 1998;37(4):437-41.

40. Kasapoglu Aksoy M, Birtane M, Taştekin N, Ekuklu G. The effectiveness of structured group education on ankylosing spondylitis patients. J Clin Rheumatol. 2017;23(3):138-43.

41. Flórez MT, Almodóvar R, García Pérez F, Rodríguez Cambrón AB, Carmona L, Pérez Manzanero MÁ, et al. The EJES-3D tool for personalized prescription of exercise in axial spondyloarthritis through multimedia animations: pilot study. Rheumatol Int. 2018;38(7):1277-84. 